\title{
High-performance Liquid Chromatography-UV
}

National Cancer Institute

\section{Source}

National Cancer Institute. High-performance Liquid Chromatography-UV. NCI

Thesaurus. Code C120693.

An analytical technique where high performance liquid chromatography with an ultraviolet light detector is used to separate, identify, and quantify substances in a sample. 